\title{
LA EXCLUSIÓN DEL EXTRANJERO. CONSIDERACIONES DE FILOSOFÍA JURÍDICA.
}

\author{
Fernando ARLETTAZ \\ INVESTIGADOR DEL LABORATORIO DE SOCIOLOGÍA JURÍDICA \\ UNIVERSIDAD DE ZARAGOZA
}

SUMARIO: I. Introducción: el sino de la exclusión. II. Un ejemplo: la reciente reforma del sistema sanitario español. III. La cuestión de fondo: derechos de los extranjeros y derechos de los nacionales. III.I. Los derechos de los extranjeros. III.2. El estatuto disminuido de los extranjeros. III.3. Cuatro explicaciones para la exclusión. IV. Conclusiones: la inseguridad de los derechos. V. Bibliografía citada.

RESUMEN: La nacionalidad es en las sociedades contemporáneas la principal fuente jurídica de exclusión del estatuto de la plena ciudadanía. El artículo analiza cuatro argumentos que permiten, de forma complementaria, explicar el modo de funcionamiento de esta exclusión. Estos argumentos (que pueden denominarse egoísta, contractualista, nacionalista y pragmático) representan a su vez diferentes concepciones acerca del vínculo de nacionalidad.

PALABRAS ClAVE: extranjeros, nacionalidad, ciudadanía.

ABSTRACT: Nationality is, in contemporary societies, the main legal source of exclusion from full citizenship. This article deals with four arguments that allow to understand the way this exclusion functions. These arguments (that can be named the selfish argument, the contractualist argument, the nationalist argument and the pragmatic argument) represent, in their turn, different conceptions about nationality.

KEYWORDS: aliens, nationality, citizenship.

\section{Introducción: el sino de la exclusión}

La coexistencia en una misma unidad política de grupos cuyos estatutos jurídicos y políticos son diferentes no es por supuesto nada nuevo. El hecho de que estos estatutos sean no sólo diferentes sino también jerárquicamente distintos tampoco. Desde la Antigüedad la historia de la humanidad ha conocido complejos mecanismos jurídicos que han significado la puesta en funcionamiento de una estructura política excluyente, dejando a buena parte de la población fuera de aquel conjunto de derechos que puede identificarse como estatuto de ciudadanía plena. 
Las economías de la Antigüedad eran economías de tipo esclavista. De hecho, la gran división de los hombres era la que los distinguía en hombres libres y esclavos. Era común que los prisioneros de guerra capturados, o incluso las personas aprehendidas en territorio ajeno aunque no hubiese mediado guerra, fueran reducidos a la esclavitud. En derecho romano, por ejemplo, eran esclavos quienes habían sido hechos prisioneros durante la guerra y también los propios ciudadanos romanos que habían incurrido en faltas penales graves. La institución de la esclavitud se mantuvo a lo largo de los siglos y tuvo, como es conocido, gran auge en el contexto del colonialismo europeo que propició el tráfico negrero. No fue sino hasta bien entrado el siglo XIX que se produjo a nivel internacional y con carácter más o menos general la abolición de la esclavitud. No obstante, incluso después de su abolición formal, el tráfico negrero continuó con la tolerancia de las potencias coloniales durante bastante tiempo ${ }^{\mathrm{I}}$.

Otra forma de exclusión fue, en el contexto de los sistemas feudales, la que afectaba a los siervos. En la Antigüedad tardía fue apareciendo gradualmente, como resultado de la transformación de la institución romana del colono, la figura del siervo que está atado a la tierra. Basta ver algunos ejemplos, como el Fuero Juzgo que data del siglo VII y sujeta el siervo a la propiedad del señor, para darse cuenta del modo en que el derecho tornaba operativa esta forma de exclusión ${ }^{2}$.

La Modernidad no supuso desde luego la eliminación de los mecanismos de exclusión. En todo caso, lo que se produjo fue una metamorfosis que agregó complejidad y sutileza a esos mecanismos. La construcción de los Estados modernos, como es sabido, se ha asentado sobre una doble base: el desarrollo de una economía de mercado y la conformación de una cierta idea de unidad cultural del sustrato social del Estado. Desde sus inicios, un obstáculo al que se enfrentó la construcción del Estado moderno fue la situación de los diferentes, es decir, de aquellos que son vistos por los grupos dominantes como poco aptos al desarrollo de la economía de mercado o ajenos a la identidad cultural presuntamente compartida.

La cuestión tiende a repetirse en diferentes lugares a lo largo de la época moderna: diversos grupos (unos $\mathrm{u}$ otros según el momento histórico) son segregados de las instituciones políticas y el sistema jurídico. Se duda de su lealtad a las instituciones y ellos son excluidos así del estatuto de plena ciudadanía del que gozan los sectores privilegiados.

La situación de subordinación sufrida por estos grupos proviene, a veces, de una directa y explícita discriminación por parte del sistema jurídico. Otras veces, en cambio, se trata de una discriminación indirecta, proveniente de un derecho que, aunque no establece un estatus jurídico formalmente disminuido para ellos, los perjudica por su carácter presuntamente uniforme y formalmente neutro que no es tal. Finalmente, hay también supuestos de estigmatización social al margen del derecho. La más de las veces, sin embargo, se trata de una mezcla de estos tres tipos de exclusión.

Bastará aquí con ver algunos ejemplos. Las comunidades aborígenes latinoamericanas fueron colocadas en un estatuto de subordinación primero por la

\footnotetext{
${ }^{\mathrm{I}}$ Ver, entre muchos otros, Finley, M. I., Ancient slavery and modern ideology, Harmondsworth, Penguin, I983. KLeIn, H. S., La esclavitud africana en América Latina y el Caribe, Madrid, Alianza, I987.

${ }^{2}$ Ver entre otros los trabajos de Bloch, M., La sociedad feudal, Madrid, Akal, i987. PéReZ-Prendes, J. M., Instituciones medievales, Madrid, Síntesis, I997.
} 
conquista europea y luego por los procesos de constitución de los Estados nacionales después de la independencia política de estos países en el siglo XIX. La conquista europea tuvo como justificación explícita la conversión de los aborígenes al catolicismo, además de una finalidad menos confesable de explotación económica ${ }^{3}$. Los Estados nacionales independientes no abandonaron la idea de asimilación religiosa, a la que agregaron el escepticismo sobre la posibilidad de integrar productivamente las comunidades aborígenes en los nacientes mercados nacionales. Esto llevó a violentas políticas de imposición cultural y religiosa, cuando no se promovió directamente el exterminio físico de los grupos indígenas.

Hacia fines del siglo XVIII, cuando se discutía en Europa la emancipación civil y política de los judíos, sus detractores decían que ella era imposible, porque consideraban a los judíos desleales y separacionistas, sostenían que adherían a una religión oscurantista, y creían que no serían buenos soldados ni ciudadanos productivos. El decreto de emancipación de los judíos adoptado por la Asamblea Nacional francesa fue el comienzo de la Modernidad judía y un ejemplo que se expandió luego por otros lugares del mundo. Sin embargo, la emancipación tuvo una contrapartida. Para ser admitidos como ciudadanos, los judíos debieron abandonar muchos de los elementos que los particularizan, y someterse a la política de uniformidad republicana.

La construcción histórica de los Estados Unidos como nación blanca, anglosajona y protestante también fue causa de exclusión. Los Padres Fundadores de la nación estadounidense habían buscado consolidar la unidad nacional sacralizando los textos constitucionales, y apoyándose en símbolos religiosos cristianos protestantes. El nacionalismo protestante excluía a los indígenas, a los negros, a los mormones, y también a los católicos y a los judíos. El protestantismo funcionaba como un factor de cohesión para los estadounidenses blancos y de origen anglosajón, un elemento de unidad y uniformidad cultural (aunque por supuesto no deben olvidarse divisiones internas, como las que separaban a las ciudades industriales y cosmopolitas del norte del sur rural y esclavista). Quienes no compartían los valores evangélicos que constituían la comunidad cívica estaban excluidos ${ }^{4}$.

Podríamos seguir con los ejemplos, pero con esto bastará por ahora. Muchas de las exclusiones que hemos mencionado han desaparecido, al menos formalmente, en los Estados democráticos contemporáneos. La esclavitud ha sido jurídicamente desterrada, los indígenas americanos han accedido a una consideración formal de igualdad y las minorías religiosas ya no tienen un estatuto jurídico disminuido.

Sin embargo, subsisten todavía factores de exclusión jurídica, y desde luego muchísimos elementos de exclusión fáctica. Aquí nos interesa particularmente hablar de la

\footnotetext{
${ }^{3}$ Sobre la justificación jurídica de la conquista ver Gomez, T., Droit de conquête et droit des indiens, Paris, Armand Colin, i996. De Courcelles, D., «Pensée théologique et événement: droit de conquête et droit des gens dans l'empire espagnol du XVIe siècle», en C. Val Julian, La conquête de l'Amérique Espagnole et la question du droit, Fontenay-aux-Roses, ENS, I996, págs.I5-31.

${ }^{4}$ Sobre la exclusión de las minorías religiosas puede consultarse, de forma meramente indicativa, LEVEY, G. B., «Secularism and religion in a multicultural age», en G. Levey y T. Modood, Secularism, religion and multicultural citizenship, Cambridge, Cambridge University Press, 20IO, págs. I-24. CASANOvA, J., «Immigration and the new religious pluralism: a European Union - United States comparison», en G. Levey y T. Modood, Secularism, religion and multicultural citizenship, Cambridge, Cambridge University Press, 2010, págs. I39-163. Nussbaum, M. C., Liberty of conscience. In defense of America's traditions of religious equality, Nueva York, Basic Books, 2009.
} 
gran fuente de exclusión jurídica todavía subsistente en las sociedades democráticas contemporáneas: la exclusión basada en la nacionalidad. Como veremos más abajo, el derecho internacional y los derechos nacionales han ido poniendo obstáculos a la posibilidad de establecer discriminaciones injustificadas sustentadas en la raza, la religión, el sexo o la orientación sexual, por señalar los casos más conocidos. Pero la discriminación por nacionalidad es todavía lícita en (me animaría a decir todos) los sistemas jurídicos. La ciudadanía, como estatuto de derechos, viene así ligada a la nacionalidad, como vínculo jurídico con el Estado5.

La existencia de un vínculo de nacionalidad crea una fractura entre la población real y la sociedad políticamente reconocida ${ }^{6}$. Esta fractura opera primeramente a nivel del sistema jurídico, pero no se agota ahí. Hay una dimensión simbólica de la exclusión (de la que el derecho es en parte reflejo y en parte causa) que tiene una trascendente repercusión a nivel de la conformación de opiniones. Probablemente desde el punto de vista de amplios sectores de la población parecería a todas luces aberrante negar el derecho a acceder a un empleo a alguien por el hecho de ser judío, negro u homosexual. De hecho los ordenamientos jurídicos de los Estados democráticos suelen establecer mecanismos para evitar este tipo de discriminaciones y sancionarlas cuando se producen, y es generalmente aceptado por la opinión pública que éste es el modo correcto de obrar. Sin embargo, reservar el acceso a ciertos empleos a los nacionales puede parecer, a esos mismos sectores de la población, la cosa más natural.

La dimensión simbólica de la exclusión permite legitimar ante la opinión pública un determinado estado de cosas que excluye de la plenitud de los derechos a los extranjeros. Pero no sólo eso: permite también que ese estado de cosas se modifique, in malam partem, con mayor facilidad que respecto de los nacionales. La dimensión simbólica de la exclusión abre la puerta a la inseguridad de los derechos: los derechos de los extranjeros son percibidos como una concesión graciosa del Estado que puede por ello revocarlos sin dar mayores explicaciones.

En el apartado siguiente vamos a estudiar un ejemplo (el de la reciente reforma sanitaria en España) de negación de derechos en razón de la nacionalidad. Se trata de un caso patente que, en el contexto de un Estado que presume de ser Estado social $y$ democrático de derecho, muestra la persistencia de la nacionalidad como factor de exclusión y la mayor facilidad con la que pueden aceptarse por algunos los argumentos en este sentido.

\section{Un ejemplo: la reciente reforma del sistema sanitario español}

Para comenzar nuestro análisis, expondremos someramente la evolución de las disposiciones legales que resultan relevantes en esta materia. Según la Ley 16/2003, de cohesión y calidad del Sistema Nacional de Salud (a partir de aquí, ley del sistema nacional de salud), en su versión original, eran «titulares de los derechos a la protección de la salud y a la atención sanitaria los siguientes: a) Todos los españoles y los extranjeros en el territorio nacional en los términos previstos en el artículo i2 de la Ley Orgánica 4/2000; b) Los

\footnotetext{
${ }^{5}$ De LuCAS, J., Puertas que se cierran: Europa como fortaleza, Barcelona, Icaria, I996, págs. 2I-22.

${ }^{6}$ Susín Betrán, R., Fronteras y retos de la ciudadanía. El gobierno democrático de la diversidad, Logroño, Perla Ediciones, 20I2, pág. 54 .
} 
nacionales de los Estados miembros de la Unión Europea que tienen los derechos que resulten del derecho comunitario europeo y de los tratados y convenios que se suscriban por el Estado español y les sean de aplicación; c) Los nacionales de Estados no pertenecientes a la Unión Europea que tienen los derechos que les reconozcan las leyes, los tratados y convenios suscritos»?.

Como se ve, la ley remitía, respecto de los extranjeros no comunitarios (inciso b) ni amparados por regímenes especiales (inciso c) a la Ley Orgánica 4/2000, es decir, la Ley sobre derechos y libertades de los extranjeros en España y su integración social (a partir de aquí, ley de extranjería). Esta ley, a su vez, disponía en su versión original lo siguiente: «I. Los extranjeros que se encuentren en España inscritos en el padrón del municipio en el que residan habitualmente, tienen derecho a la asistencia sanitaria en las mismas condiciones que los españoles. 2. Los extranjeros que se encuentren en España tienen derecho a la asistencia sanitaria pública de urgencia ante la contracción de enfermedades graves o accidentes, cualquiera que sea su causa, y a la continuidad de dicha atención hasta la situación de alta médica. 3. Los extranjeros menores de dieciocho años que se encuentren en España tienen derecho a la asistencia sanitaria en las mismas condiciones que los españoles. 4. Las extranjeras embarazadas que se encuentren en España tendrán derecho a la asistencia sanitaria durante el embarazo, parto y postparto».

En síntesis, tenían derecho a la atención sanitaria en las mismas condiciones que los españoles los extranjeros menores de i8 años (cualquiera que fuera su situación administrativa) y los extranjeros (cualquiera que fuera su situación administrativa) que estuvieran inscriptos en el padrón del municipio en el que residan habitualmente. Los extranjeros no comprendidos en estas categorías, tenían derecho a la atención sanitaria en dos supuestos: tratándose de enfermedades graves o accidentes, respecto de la atención sanitaria de urgencia; y tratándose de mujeres embarazadas, respecto de la atención durante el embarazo, parto y posparto. Una reforma posterior cambió el requisito de estar inscripto en el padrón del municipio de su «residencia habitual» por el requisito de estar inscripto en el padrón del municipio de su «domicilio habitual»?

Pero más allá de las características particulares del orden jurídico en este aspecto, aquí nos interesa resaltar dos cosas. En primer lugar, la distinción que este ordenamiento hace entre nacionales y extranjeros. En segundo lugar, la distinción que se hace, al interior de la categoría de los extranjeros, entre diferentes subcategorías. Volveremos sobre esto más abajo.

El Real Decreto-Ley I6/20I2, denominado eufemísticamente de medidas urgentes para garantizar la sostenibilidad del Sistema Nacional de Salud y mejorar la calidad y seguridad de sus prestaciones, reformó tanto la ley de extranjería como la ley del sistema nacional de salud. Respecto de la primera, se estableció que «los extranjeros tienen derecho a la asistencia sanitaria en los términos previstos en la legislación vigente en materia

\footnotetext{
${ }^{7}$ Artículo 3 Ley i6/2003, de 28 de mayo, de cohesión y calidad del Sistema Nacional de Salud (BOE de 29 de mayo de 2003), versión original.

${ }^{8}$ Artículo I2 Ley Orgánica 4/2000, de in de enero, sobre derechos y libertades de los extranjeros en España y su integración social (BOE de I de febrero de 2000), versión original.

${ }^{9}$ Artículo I2 Ley Orgánica 4/2000, según redacción dada por Ley Orgánica 2/2009, de in de diciembre, de reforma de la Ley Orgánica 4/2000, de in de enero, sobre derechos y libertades de los extranjeros en España y su integración social (BOE de I2 de diciembre de 2009).
} 
sanitaria $»^{\mathrm{I0}}$. Es decir, remitió simplemente a ley del sistema nacional de salud. Ésta, a su vez, establece en su nueva redacción que la asistencia sanitaria a través del sistema nacional de salud se garantiza a aquellas personas que tengan condición de asegurados. Y que para ello es necesario estar incluido en alguna de las siguientes categorías: «a) ser trabajador por cuenta ajena o por cuenta propia, afiliado a la Seguridad Social y en situación de alta o asimilada a la de alta; b) ostentar la condición de pensionista del sistema de la Seguridad Social; c) ser perceptor de cualquier otra prestación periódica de la Seguridad Social, incluidas la prestación y el subsidio por desempleo; d) haber agotado la prestación o el subsidio por desempleo y encontrarse en situación de desempleo, no acreditando la condición de asegurado por cualquier otro título». La Ley de Presupuestos para 20I4 introdujo algunos cambios en el último inciso, de manera que ahora tienen derecho a la asistencia sanitaria quienes se encuentren en situación de desempleo y no acrediten la condición de asegurado por cualquier otro título, siempre que hayan agotado la prestación o el subsidio por desempleo «u otras prestaciones de similar naturaleza» y «resid[an] en España» ${ }^{\mathrm{II}}$.

Si no se pertenece a ninguna de estas categorías, todavía es posible ostentar la condición de asegurado para «las personas de nacionalidad española o de algún Estado miembro de la Unión Europea, del Espacio Económico Europeo o de Suiza que residan en España y los extranjeros titulares de una autorización para residir en territorio español, (...) siempre que acrediten que no superan el límite de ingresos determinado reglamentariamente» ${ }^{12}$. Las personas que no tengan la condición de asegurado ${ }^{13}$ sólo podrán $^{2}$ acceder a la asistencia sanitaria mediante el pago de una contraprestación derivada de la suscripción de un convenio especial ${ }^{\mathrm{T}}$.

Dicho sintéticamente, en virtud del Real Decreto-Ley I6/20I2 que establece medidas de reducción del gasto en materia sanitaria, se priva del acceso al sistema nacional de salud a los extranjeros no comunitarios que se encuentren en situación administrativa irregular en España. Sin embargo, se incluyeron tres excepciones que permiten a los extranjeros en situación irregular recibir atención sanitaria: «a) de urgencia por enfermedad grave o accidente, cualquiera que sea su causa, hasta la situación de alta médica; b) de asistencia al embarazo, parto y postparto»; c) si se trata de menores de I8 años, en cualquier caso y en condiciones de igualdad con los españoles ${ }^{15}$.

Como se ve, la nueva regulación no sólo mantiene la diferenciación entre nacionales y extranjeros, sino que además agrava la situación de estos últimos en relación con los primeros. Ante esta drástica limitación al acceso a la atención sanitaria por parte de los

\footnotetext{
${ }^{10}$ Artículo I2 Ley Orgánica 4/2000, según redacción dada por Real Decreto-ley I6/2012, de 20 de abril, de medidas urgentes para garantizar la sostenibilidad del Sistema Nacional de Salud y mejorar la calidad y seguridad de sus prestaciones (BOE de 24 de abril de 2012 ).

${ }^{\text {II }}$ Artículo 3 Ley I6/2003, según redacción dada por Ley 22/20I3, de 23 de diciembre, de Presupuestos Generales del Estado para el año 2014 (BOE de 26 diciembre de 20I3).

${ }^{12}$ Artículo 3 Ley i6/2003, según redacción dada por Real Decreto-Ley i6/2012.

${ }^{13} \mathrm{O}$ de beneficiarios de un asegurado (que incluye al cónyuge o persona con análoga relación de afectividad con un asegurado, el ex cónyuge a cargo del asegurado, así como los descendientes y personas asimiladas a cargo del mismo que sean menores de 26 años o que tengan una discapacidad en grado igual o superior al 65\%). Artículo 3 Ley I6/2003, según redacción dada por Real Decreto-Ley I6/20I2.

${ }^{14}$ Artículo 3 Ley I6/2003, según redacción dada por Real Decreto-Ley I6/20I2.

${ }^{15}$ Artículo 3 ter Ley 16/2003, según redacción dada por Real Decreto-Ley 16/2012.
} 
extranjeros en situación administrativa irregular en el territorio español, algunos colectivos comenzaron a promover la negativa al cumplimiento de las nuevas medidas. Tal fue el caso de la Sociedad Española de Medicina de Familia y Comunitaria (SEMFyC), que realizó un llamado a la negativa que calificó como objeción de conciencia, y puso a disposición de los interesados un formulario on-line ${ }^{16}$ que podría ser completado por quienes estuvieran dispuestos a no cumplir con la nueva normativa y que sería enviado al Servicio de Salud correspondiente (sin incluir Andalucía, Asturias, Cataluña y el País Vasco, que anunciaron su intención de no aplicar la normativa).

Aunque la SEMFyC insiste en denominar su posición como un caso de objeción de conciencia, parece más claro calificarlo de desobediencia civil. Como es sabido, lo que diferencia la objeción de conciencia de la desobediencia civil es que para la primera existe un amparo jurídico, mientras que la segunda carece de esa cobertura y se fundamenta en razones meta-jurídicas (de tipo político, ético, religioso, etc. ${ }^{\text {r7 }}$.

En este caso no existe una cobertura legal ni constitucional que permita a los funcionarios del sistema nacional de salud eximirse de cumplir la normativa que restringe el acceso de determinadas personas a ese servicio. Estamos, pues, ante un caso de desobediencia civil. En cualquier caso, y más allá de las diferencias terminológicas, parece claro que los médicos que se niegan a cumplir con la norma alegan fuertes razones éticas para obrar de ese modo ${ }^{18}$. Por ejemplo, invocan que la asistencia sanitaria debe darse a todos, con independencia de su situación administrativa, laboral, social o económica al menos en lo que se denomina mínimo decente, mientras que el nuevo régimen legal limita la atención de los extranjeros en situación irregular a la que pueda ser calificada de urgente, que es menos que el mínimo decente.

Aunque opciones como la señalada puedan ser éticamente valiosas desde un punto de vista individual o grupal, ellas no deben hacernos olvidar el fondo del asunto. Y éste no es sino el relativo a la pregunta por los derechos de los extranjeros. ¿Por qué se reconoce a los nacionales derechos de los que no gozan los extranjeros? ¿Por qué parece más aceptable, en épocas de crisis, recortar derechos a los extranjeros que a los nacionales? ¿Por qué incluso muchos de quienes se oponen a estos recortes sólo atacan algunas manifestaciones

\footnotetext{
${ }^{16}$ Según la información disponible al momento de redactar este trabajo, más de I200 profesionales habían manifestado su oposición al cumplimiento de las medidas restrictivas.

${ }^{17}$ La objeción de conciencia es la excepción al cumplimiento de un deber legal otorgada por motivos de conciencia, que pueden ser motivos religiosos o éticos. El elemento fundamental que distingue a la objeción de conciencia de otras figuras próximas es que ella se encuentra habilitada por una disposición jurídica. PECEsBARBA, G., «Introducción», en G. Peces-Barba, Ley y conciencia. Moral legalizada y moral crítica en la aplicación del derecho, Madrid, Universidad Carlos III, I993, págs. I2-I4. Esta norma legal puede ser un texto expreso, o puede ser una interpretación jurisprudencial o administrativa a partir de un genérico texto constitucional. La desobediencia civil, en cambio, consiste en uno o varios actos de no obediencia a un derecho que se considera injusto, obviamente sin una autorización legal para desobedecer. Una cuestión diferente es la de la justificación ética de la desobediencia. Desde una perspectiva ética, la desobediencia civil podrá estar o no justificada según las circunstancias del caso y los bienes en juego.

Hay una diferencia también basada en la motivación: la norma que se desobedece se considera universalmente injusta, y se desobedece en la esperanza de que otros también lo hagan y la norma sea modificada. Esto, sin embargo, no sucede en la objeción de conciencia: el objetor no tiene una aspiración universal respecto de la norma, sólo pide que no le sea aplicada en su caso en razón de sus particulares motivos de conciencia.

${ }^{18}$ Sociedad Española de Medicina de Familia y Comunitaria - Grupo de trabajo de bioética, Análisis ético ante la retirada de asistencia sanitaria a inmigrantes sin permiso de residencia, $20 \mathrm{I} 2$.
} 
superficiales de la distinción entre nacionales y extranjeros, y no el principio mismo de tal distinción? $?^{\mathrm{I} 9}$.

\section{La cuestión de fondo: derechos de los extranjeros y derechos de los nacionales}

\section{III.I. Los derechos de los extranjeros}

Como hemos puesto de manifiesto, las actitudes de desobediencia civil como las propiciadas por la Sociedad Española de Medicina de Familia y Comunitaria, pueden tener una sólida justificación ética frente a una normativa legal que resulta palmariamente injusta. Sin embargo, tal tipo de reacciones puntuales frente a casos límite como puede ser el de la exclusión del sistema sanitario a alguien que requiere imperiosamente asistencia médica, no debe hacer olvidar la cuestión de fondo, relativa a la limitación de los derechos de los extranjeros y la situación de inseguridad en la que éstos se hallan sobre el estatuto de sus derechos. Lo que subyace a este debate es la pregunta siguiente: ¿por qué los extranjeros no tienen los mismos derechos que los nacionales?

Una pregunta casi idéntica sirvió de título a un artículo del profesor García Amado $^{20}$, publicado en 2003. Más abajo analizaremos con más detalle sus argumentaciones. Antes, sin embargo, diremos algunas palabras sobre cómo funciona, al interior del ordenamiento jurídico, la exclusión que afecta a los extranjeros.

En la introducción nos hemos referido a la construcción del Estado moderno, y lo que eso implicó en términos de exclusión. Lo que debe ser señalado es que las exclusiones sobre las que se basó esa construcción convivieron (y conviven) con un discurso universalista de los derechos humanos. Es verdad que la mayoría de las exclusiones jurídicas al estatuto de la ciudadanía han sido formalmente superadas en los ordenamientos de los Estados democráticos. Por supuesto subsisten todavía importantes exclusiones fácticas derivadas del sexo, la pertenencia a un grupo étnico o religioso, o la clase social, por citar sólo algunas. Y subsiste también, y de esto nos ocupamos aquí, la exclusión jurídica derivada del vínculo de la nacionalidad.

La regulación de los derechos de los extranjeros corresponde, según establece el derecho internacional hoy vigente, al Estado en cuyo territorio o bajo cuya autoridad se encuentran esos extranjeros. El principio general en esta materia es que dado que no existe un criterio uniforme en el derecho internacional general, cada Estado es soberano para determinar las condiciones de entrada, permanencia y salida de los extranjeros de su territorio, así como los derechos que le reconoce a los extranjeros que se encuentran en ese territorio. En efecto, dos son los aspectos fundamentales por los que se interesa el derecho internacional, y que deben ser mencionados aquí. El primero es el de la entrada, permanencia y salida de una persona del territorio de un Estado diferente al de su nacionalidad. El segundo presupone ya que la persona se encuentra en un Estado diferente

\footnotetext{
${ }^{19}$ Hay que recordar que la SEMFyC se opone a que se recorte la asistencia sanitaria a los extranjeros que ya estén en territorio español, pero no a quienes podrían llegar a partir de ahora en situación irregular. Ver el documento citado en la nota anterior.

${ }^{20}$ García Amado, J. A., «¿Por qué no tienen los inmigrantes los mismos derechos que los nacionales?», Revista de Derecho Migratorio y Extranjería, 3, 2003, págs. 9-28. A pesar del título, el contenido del artículo está referido al tema del que nos ocupamos aquí, que es el de los derechos de los extranjeros (ya sean inmigrantes, hijos de inmigrantes, residentes temporarios sin intención de migrar definitivamente, etc.).
} 
al de su nacionalidad (de manera legal o ilegal), y lleva a preguntarse acerca de cuáles son los derechos sustantivos que se le reconocen ${ }^{21}$.

Respecto de la admisión de los nacionales de un Estado en el territorio de otro es generalmente sostenido que no hay ninguna norma de derecho internacional que con carácter general obligue a un Estado a aceptar en su territorio a nacionales de otros Estados. Respecto de la salida, se admite también que los Estados están legitimados para proceder tanto a acciones de devolución (cuando un extranjero ingresa de modo ilegal al territorio de un Estado, o intenta hacerlo, el Estado puede conducirlo al territorio del Estado del que sea nacional o del que proceda) como de expulsión (si el extranjero tiene el derecho a permanecer en el territorio y de lo que se trata es removerlo del territorio tras la extinción o la revocación de ese derecho).

La costumbre internacional reconoce algunos límites a esta potestad del Estado, aunque éstos son muy reducidos. Así, de acuerdo con el principio de no-devolución o nonrefoulement, el Estado no puede devolver a un extranjero al territorio de otro Estado en el que corra riesgos por motivos raciales, religiosos, políticos, etc. Igualmente, respecto de la expulsión, el derecho internacional impone ciertas condiciones para que pueda considerarse legítima. Aunque el poder del Estado territorial es muy amplio, éste no puede incurrir en situaciones de arbitrariedad y suele también reconocerse el derecho del interesado a un recurso frente a la decisión de expulsión, así como la garantía de que ésta no sea ejecutada de modo excesivamente rápido o vejatorio.

El segundo aspecto es el de los derechos de que gozan los extranjeros en el territorio de un Estado, dando por supuesto que ya se encuentran en él. También en este ámbito es el propio Estado territorial el que determina cuáles son los derechos que puede reclamar un extranjero. Sin embargo, el derecho internacional general impone aquí el respeto a un estándar mínimo. Aunque el contenido de este estándar es difícil de precisar y depende en buena medida de la casuística, en general se admite que corresponde a la media de los países civilizados. El Estado no puede imponer a los extranjeros vejaciones o torturas, no debe someterlos a requisiciones arbitrarias, debe permitirles ponerse en contacto con las autoridades de su Estado, debe protegerlos contra vejaciones o ataques que provengan de particulares, debe darles los medios judiciales de protección frente a conductas ilícitas, etc.

Hasta aquí hemos señalado el estado de la cuestión en derecho internacional general, es decir en el derecho internacional consuetudinario de carácter general. El Estado puede, sin embargo, auto-restringir su soberanía en este ámbito por medio de tratados internacionales. Éstos, en lo que aquí nos interesan, pueden ser de dos clases.

En primer lugar, los tratados internacionales de derechos humanos pueden reconocer derechos a los extranjeros. Los tratados internacionales de derechos humanos de carácter general, en efecto, se refieren a algunos derechos que corresponden a toda persona, sin distinción alguna por razón de nacionalidad; e incorporan también algunos derechos específicos de los extranjeros, como por ejemplo la protección contra las expulsiones

\footnotetext{
${ }^{21}$ Respecto de esta temática puede consultarse los textos sistemáticos de derecho internacional. QuOC DiNH, N., Droit international public, Paris, Librairie Générale de Droit et de Jurisprudence, I994, págs. 658-666. Combacau, J. y Sur, S., Droit International Public, París: Montchrestien, I999, págs. 36I-374. Díez de Velasco, M., Instituciones de Derecho Internacional Público, Madrid, Tecnos, 2007, págs. 6ir-6i7. Remiro Brotóns, A., Derecho Internacional, Valencia, Tirant lo Blanch, 2007, págs. 83I-843. PASTOR Ridruejo, J. A., Curso de Derecho Internacional Público y Organizaciones Internacionales, Madrid, Tecnos, 20I2, págs. 235-243.
} 
$\operatorname{arbitrarias}^{22}$. Otros tratados internacionales de derechos humanos están referidos específicamente a la situación de los extranjeros ${ }^{23}$.

En segundo lugar, los Estados pueden firmar también tratados bilaterales o multilaterales de amistad, cooperación o integración, que incluyan algunos derechos a favor de los nacionales de los Estados parte que se encuentren en el territorio de otro Estado parte o que quieran acceder a él. La casuística aquí es muy amplia, ya que los derechos varían de tratado a tratado. El caso más antiguo es seguramente el de los tratados bilaterales de amistad y comercio, que solían brindar condiciones favorables al establecimiento de extranjeros en la medida en que éstos fueran trabajadores autónomos o inversores. Hoy el ejemplo más acabado son los tratados de integración.

Estos tratados pueden asumir múltiples formas. De modo general, puede establecerse una tipología con cuatro clases de cláusulas posibles:

- la cláusula de trato nacional, por la que un Estado se obliga a dar a los nacionales de otro Estado el tratamiento que da a sus propios nacionales;

- la cláusula de trato internacional, según la cual el Estado otorga a los extranjeros los derechos reconocidos en el propio tratado;

- la cláusula de reciprocidad, según la cual el tratamiento que un Estado otorga a los nacionales del otro depende del tratamiento que este segundo otorga a los nacionales del primero;

- la cláusula de nación más favorecida, por la cual un Estado se obliga a otorgar a los nacionales de otro Estado todos los derechos que reconoce a los extranjeros que se encuentren en la posición más favorable.

\section{III.2. El estatuto disminuido de los extranjeros}

Si contrastamos nuestra somera descripción del derecho internacional hoy vigente con el derecho internacional clásico de comienzos de la Modernidad podremos ver en qué medida el derecho internacional ha sido y es un artefacto construido a la medida de las potencias centrales. En efecto, en los albores de la Modernidad Francisco de Vitoria había postulado la existencia de un ius comunicationis que permitía a las personas viajar a territorios diferentes de los de su Estado y establecerse allí, con la condición de que no causaran daños a los naturales de ese territorio ${ }^{24}$. Decía literalmente De Vitoria: «En todas las naciones se tiene por inhumano el tratar mal, sin motivo alguno especial, a los

${ }^{22}$ Ver por ejemplo Declaración Universal de los Derechos Humanos, artículo I3. Pacto Internacional de Derechos Civiles y Políticos, artículo I2. Convenio Europeo de Derechos Humanos, protocolo 4 artículos 2 y 3, y protocolo 7 artículo I. Convención Americana de Derechos Humanos, articulo 22.

${ }^{23}$ Así, en el ámbito de la OIT se debe señalar el Convenio 66 (Convenio relativo al reclutamiento, colocación $Y$ condiciones de trabajo de los trabajadores migrantes) de I939, que nunca entró en vigor y que fue reemplazado por el Convenio 97 (Convenio relativo a los trabajadores migrantes) de I949, este último a su vez completado por el Convenio I43 (Convenio sobre las migraciones en condiciones abusivas y la promoción de la igualdad de oportunidades $y$ de trato de los trabajadores migrantes) de I975. En el ámbito de las Naciones Unidas se adoptó, en I990, la Convención internacional sobre la protección de los derechos de todos los trabajadores migratorios $y$ de sus familiares.

${ }^{24}$ De Vitoria, F., Sobre el poder civil; Sobre los indios; Sobre el derecho de la guerra, Madrid, Tecnos, 2007, págs. I27-I5O. 
huéspedes y transeúntes y, por el contrario, es de humanidad y cortesía portarse bien con los extranjeros» ${ }^{25}$.

Este ius communicationis fue usado como argumento por los Estados europeos para justificar la colonización del Nuevo Mundo y la construcción de vastos imperios coloniales. De hecho, Francisco de Vitoria se refirió al ius communicationis para justificar los títulos por los cuales los bárbaros podían ser sometidos al poder de los españoles. Y aunque en principio De Vitoria incorporaba la restricción relativa a que el ius communicationis no puede ejercerse en daño de los naturales, luego admitía la licitud de la guerra contra éstos, si no aceptaban que los españoles ejercitasen su derecho de circulación y establecimiento, porque «si, después de haberlo intentado [el circular y establecerse] por todos los medios [pacíficos], los españoles no pueden conseguir la seguridad de parte de los bárbaros, si no es ocupando sus ciudades y sometiéndolos, pueden lícitamente hacerlo» ${ }^{26}$.

Como decíamos, el argumento del ius communicationis fue usado para justificar el establecimiento de los europeos en América. Sin embargo, cuando los Estados europeos pasaron de ser exportadores de colonos a receptores de inmigrantes el mismo argumento ya no les pareció tan convincente como antes. De hecho, el derecho internacional establece ahora exactamente lo contrario: que no hay un derecho a entrar y permanecer en el territorio de un Estado que no sea el propio.

Este cambio en la configuración del derecho internacional se fue dando desde fines del siglo XIX y comienzos del XX. Desde entonces se ha dado también una segunda transformación, que viene a superponerse a la primera, y que se refiere al perfil del extranjero del que se ocupa el derecho internacional ${ }^{27}$. En el siglo XIX el derecho internacional se interesaba por el extranjero civilizado, es decir, por la protección de los nacionales de los Estados occidentales que se instalaban en Asia o América Latina (y, sobre todo, por la protección de la propiedad privada de éstos). En el siglo XX, el foco está puesto en el extranjero bárbaro, el inmigrante que va de los países pobres a los países ricos.

El cambio de foco ha significado también un cambio de la estructura de la normativa, que ha ido de la protección de los intereses de las potencias coloniales e imperialistas a través de la protección de sus nacionales en tierra extraña a una restricción de los derechos de los extranjeros finamente matizada por algunas disposiciones del derecho internacional de los derechos humanos. En efecto, los tratados internacionales de derechos humanos, aunque establecen algunos derechos comunes a nacionales y extranjeros, no impiden que sobre la base de la nacionalidad se articulen algunas discriminaciones que serían impensables sobre otras bases como la raza, la religión o el sexo.

\footnotetext{
${ }^{25}$ De Vitoria, F., Sobre el poder civil; Sobre los indios; Sobre el derecho de la guerra, cit., pág. I3O.

${ }^{26}$ De Vitoria, F., Sobre el poder civil; Sobre los indios; Sobre el derecho de la guerra, cit., pág. I37. Además, junto al ius communicationis hay otro título para el establecimiento de los españoles en América, que es la propagación del Evangelio. Por eso, también es lícito hacer la guerra si los bárbaros impidieran la anunciación del Evangelio, impidieran las conversiones o intentaran que los indios conversos volvieran a la idolatría. DE ViTORIA, F., Sobre el poder civil; Sobre los indios; Sobre el derecho de la guerra, cit., págs. I39-I42.

${ }_{27}$ Remiro Brotóns, A., Derecho Internacional, cit., págs. 831-833. Estas reflexiones se refieren fundamentalmente al derecho internacional general y, también, al derecho internacional de los derechos humanos. Los tratados bilaterales o multilaterales de los que hablamos más arriba responden a otra lógica, y constituyen una especie de micro-clima en el contexto general al que nos referimos aquí.
} 
La complejidad de la situación legal de los extranjeros, que nosotros no hemos expuesto más que en sus líneas generales y refiriéndonos sólo a los grandes principios, pone de manifiesto que ellos se encuentran, en relación con los nacionales, en una situación de disminución de su estatuto de ciudadanía. Sin embargo la exclusión de los extranjeros del estatuto de ciudadanos plenos no se articula en forma de exclusión binaria, sino que se da por grados. En otras palabras, no se trata de una distinción de todo o nada, sino de la constitución de un sistema con diferentes categorías. Así, los ordenamientos jurídicos nacionales realizan una compleja atribución de derechos según la cual hay determinados derechos que se conceden a ciertas categorías y no a otras. La conformación de las diferentes categorías es generalmente realizada por los ordenamientos internos a partir de las obligaciones que les imponen los tratados internacionales a los que hicimos referencia más arriba.

La categoría jurídica más favorecida es la de los nacionales. En principio, y dado que ya se han superado las barreras jurídicas de las que hablamos más arriba, no hay distinciones internas en este grupo, por lo que todos los nacionales gozan del mismo estatus formal de ciudadanía plena y se benefician también plenamente del principio de igualdad ante la ley.

El salto cualitativo se opera, al menos en teoría, entre la categoría de los nacionales y la de los extranjeros. Sin embargo, no todos los extranjeros están en la misma situación. Inmediatamente por debajo de los nacionales se encuentran los extranjeros que tienen un estatus protegido por tratados internacionales, de modo que el orden jurídico interno del Estado no puede, sin incurrir en responsabilidad internacional, negarle los derechos que están previstos en esos tratados.

En la categoría de extranjeros con derechos emergentes de tratados internacionales puede haber infinidad de sub-categorías específicas, que dependerán del contenido de esos tratados. Así, los derechos reconocidos pueden ir desde una simple exención de visado para ingresar al país como turista hasta una asimilación casi total con el estatuto de ciudadanía de los nacionales, como sucede en general en los procesos de integración del que la Unión Europea es el ejemplo más acabado.

En la tercera categoría se encontrarían aquellos extranjeros cuyos derechos no están protegidos por tratados internacionales, de modo que su estatuto jurídico depende íntegramente de lo que el Estado esté dispuesto a reconocerles (con las salvedades de las que ya hablamos). Por supuesto, la categoría anterior y ésta pueden superponerse, ya que en todo aquello que no sea materia de tratados internacionales el Estado gozará de libertad para delimitar el estatuto de los extranjeros.

Dentro de esta tercera categoría también puede haber infinidad de sub-categorías, que dependerán de los criterios establecidos por el derecho interno. Así, los Estados suelen ampliar el estatuto de derechos de los extranjeros a medida que aumenta el tiempo en que éstos han residido en el territorio. En cualquier caso, la distinción más importante dentro de esta categoría es la que se opera entre extranjeros que residen en situación regular dentro del Estado y los que se encuentran en situación irregular. En efecto, los Estados imponen reglas que deben ser cumplidas para que el ingreso y la permanencia de una persona en su territorio puedan ser considerados lícitos. Si estos criterios no están cumplidos, los extranjeros se encontrarán en situación irregular y sus derechos serán los 
que el propio Estado establezca para esta categoría de extranjeros, los que en general son muy limitados.

\section{III.3. Cuatro explicaciones para la exclusión}

Vayamos ahora al fondo del asunto. Ya hemos visto que los extranjeros gozan de un estatus limitado en relación con los nacionales. También hemos visto, a través del ejemplo que hemos citado, que resulta más aceptable para la opinión general que se restrinjan los derechos de los extranjeros antes de que se restrinjan los derechos de los nacionales. ¿Por qué es esto así?

En el ya citado trabajo del profesor García $\mathrm{Amado}^{28}$, éste ofrece tres justificaciones posibles para la exclusión. Se trata de tres argumentos que podrían permitir justificar la reducción del estatuto de derechos de los extranjeros en relación con los nacionales. La primera justificación que menciona es la propia del nacionalismo sustancializador, según la cual los extranjeros no han de tener los mismos derechos que los nacionales porque los primeros no forman parte de la nación, y es precisamente la nación el sustrato que da sentido al Estado y aglutina a sus nacionales. La segunda es propia del egoísmo insolidario, que reconoce que ninguna razón sustancial sino sólo la pura casualidad y el azar histórico han hecho que determinadas personas sean nacionales de un determinado Estado. Sin embargo, dado que existen Estados, existen nacionales y nosotros (los nacionales del Estado $\mathrm{X})$ tenemos el poder para dirimir si permitimos o no que los nacionales del Estado $\mathrm{Y}$ vengan a vivir con nosotros y, en caso de venir, decidir qué derechos les reconoceremos, decidimos permitirles venir si y sólo si ello favorece nuestro interés, y decidimos reconocerles los derechos que sean necesarios, y ninguno más, para satisfacer nuestro interés. Para el egoísta insolidario el Estado nacional no es una entidad sustantiva, sino sólo un instrumento de protección de sus intereses. La tercera opción es la de la existencia de motivos puramente pragmáticos que justificarían las restricciones a la entrada de los extranjeros, así como al estatuto de sus derechos.

El trabajo del profesor García Amado resulta muy sugerente, y nosotros seguiremos algunos de sus postulados. Sin embargo, organizaremos las posibles justificaciones de modo algo diferente. Además, estos argumentos pueden ser analizados no sólo como argumentos normativos para justificar la exclusión de derechos de los extranjeros, sino también como argumentos explicativos que permitan comprender algunas características concretas de las opciones políticas de los Estados en materia de extranjería. Aquí nos dedicaremos a lo segundo, y dejaremos los aspectos normativos para la conclusión de este trabajo.

La primera justificación posible es la del propio interés de los nacionales. Se trata, efectivamente, de una justificación egoísta: recibiremos en nuestro país a los extranjeros que nos resulte conveniente recibir (y ni uno más), les permitiremos vivir aquí por el tiempo que nos resulte conveniente (y ni un día más) y les reconoceremos los derechos que nos resulte conveniente reconocerles (y ni uno más).

\footnotetext{
${ }^{28}$ García AmAdo, J. A., «¿Por qué no tienen los inmigrantes los mismos derechos que los nacionales?», cit., págs. II-I2.
} 
Aunque la justificación basada en el interés de los propios nacionales puede adquirir diversas formas, la más habitual es la de tipo económico. Es una evidencia que existen países más ricos que otros, y por eso también resulta claro que acceder al mercado de trabajo de los países más ricos representa para quienes vienen de los países más pobres una oportunidad de mejorar su situación. Ahora bien, siendo los puestos de trabajo disponibles en un mercado nacional por definición limitados, el acceso de los extranjeros debe limitarse en beneficio de los nacionales.

Así, el argumento del nacional del país más rico puede ser: los extranjeros podrán venir a nuestro país en la medida en que sean necesarios para cubrir puestos para los que no hay suficientes personas cualificadas entre los nuestros o para los que no hay suficientes personas dispuestas entre los nuestros.

En el caso de economías de mercado, esta justificación tiene mucho que ver con las reglas de funcionamiento propias del mercado. Así, sólo los más cualificados podrán acceder al premio que significa obtener un permiso para entrar y permanecer en el Estado. Y podrán mantener ese permiso en la medida en que puedan probar que siguen siendo productivos.

Sin embargo, hay que recordar que de lo que se trata no es de proteger el libre funcionamiento del mercado, sino de proteger nuestro interés (egoísta) en ese mercado. Si de lo que se tratara fuera de proteger el libre funcionamiento del mercado, cualquier restricción a la entrada y permanencia de extranjeros debería ser eliminada. El propio mercado se encargaría de dejar que los más cualificados y productivos desplazaran a los menos aptos.

Esta lógica es la que Javier de Lucas ha llamado lógica del regateo y de la segmentación: se trata de reconocer a los extranjeros sólo los derechos mínimos e indispensables para que puedan ejercer su función de trabajadores migrantes. Es una lógica de carrera de obstáculos, discrecionalidad de la administración y discriminación. El inmigrante es un extraño sobre el que está suspendida la universalidad de los derechos y que sólo es considerado positivamente en la medida que aporta su trabajo. Para el extranjero no valen las reglas del Estado de Derecho, sino sólo las del derecho penal del enemigo ${ }^{29}$.

Una segunda explicación puede formularse en términos contractuales, del siguiente modo: los nacionales que han nacido y viven en el territorio del Estado han dado implícitamente su consentimiento en obligarse a través de un pacto social que los involucra, y como han consentido en someterse a las obligaciones que les impone el pacto, también es legítimo que disfruten de sus derechos.

Una tercera explicación sería la del esencialismo nacionalista del que hablamos más arriba. El nacionalismo supone que la nación es una unidad que trasciende a los individuos que la forman. La lengua, la cultura, las formas de vida de un grupo social no son, para el nacionalista, el resultado más o menos azaroso de una sedimentación histórica, sino la esencia misma de un grupo nacional. Al mismo tiempo, el grupo preexistiría a sus miembros, que pueden llamarse nacionales gracias, justamente, a su inclusión en el todo completo y acabado que es la nación. Por ello, los extranjeros, en cuanto no forman parte de ese conjunto orgánico que es la nación no pueden aspirar a tener los derechos que tienen

\footnotetext{
${ }^{29}$ DE LuCAS, J., «Nuevas estrategias de estigmatización. El Derecho, frente a los inmigrantes», en G. Portilla, Mutaciones de Leviatán. Legitimación de los nuevos modelos penales, Madrid, Akal, 2005, págs. 205-2I9. De LUCAS, J., «Inmigrantes. Del estado de excepción al Estado de derecho», Oñati Socio-Legal Series, I-3, 2OII, págs. I-I4.
} 
los nacionales, ni a vivir en el territorio que, también esencialmente, le corresponde a la nación.

El argumento nacionalista apela a las raíces mismas del Estado-nación. La construcción del Estado nacional estuvo unida a la construcción de una conciencia nacional. Como señala Jürgen Habermas ${ }^{3^{\circ}}$, fue la nación la que permitió la emergencia de un nexo de solidaridad entre personas que hasta entonces habían sido extrañas las unas a las otras. Para la movilización política que implicaba la construcción del Estado era necesario un sustrato que le diera vida ${ }^{31}$.

En realidad, si se miran de cerca, la segunda y la tercera explicaciones no son tan diferentes (aunque a primera vista puedan parecerlo). Son dos variantes del mismo tema: el tema de la lealtad ${ }^{32}$. En la segunda explicación, el extranjero no puede tener los mismos derechos que los nacionales porque no ha demostrado su lealtad al contrato social. En el tercer caso, porque no ha demostrado su lealtad a la nación. La lealtad al contrato se demuestra mediante el sometimiento a las leyes del país, de modo que si el extranjero quiere tener los derechos que tienen los nacionales ha de demostrar que está dispuesto a cumplir con sus deberes. La lealtad a la nación se demuestra mediante a la asimilación: si el extranjero quiere tener los mismos derechos que los nacionales habrá de aprender la lengua del país, asumir sus tradiciones, convertirse a su credo.

De alguna manera, la explicación contractualista es la variante racionalista del tema de la lealtad, mientras que la explicación esencialista es su variante romántica. Con todo, las similitudes también tienen su límite. Posiblemente el contractualista esté dispuesto más fácilmente a reconocer derechos a los extranjeros en la medida en que éstos demuestren efectivamente su lealtad al contrato social; en cambio, un nacionalista recalcitrante puede que no esté nunca dispuesto a reconocer esos derechos, porque si su comprensión esencialista de la nación es fuerte y coherente consigo misma puede pensar que ella es un todo orgánico del que sólo pueden ser parte quienes han nacido en su seno. En otras palabras, el contractualista normalmente admitirá que todos aquellos que estén dispuestos a

${ }^{30}$ Habermas, J., Más allá del Estado nacional, Madrid, Trotta, 200I, págs. I76-I79.

${ }^{31}$ La idea de la necesidad de un sustrato cultural como prerrequisito para la formación de los lazos de solidaridad que son necesarios al funcionamiento del Estado reaparece en los escritos de los comunitaristas contemporáneos. Charles Taylor pone de manifiesto que el mayor riesgo de la deriva subjetivista de nuestro tiempo es la fragmentación. La gente se vuelve cada vez más incapaz de aceptar propósitos comunes y llevarlos a cabo, lo que produce finalmente una falta de identificación con la sociedad como comunidad. TAYLOR, C., The Ethics of Authenticity, Cambridge, Harvard University Press, I99I, págs. I09-I2I. Taylor quiere resaltar que una democracia sólo puede funcionar si la mayoría de sus miembros están convencidos de que su sociedad política es una empresa común de considerable trascendencia. Piénsese por ejemplo en las políticas redistributivas: para que ellas puedan funcionar es necesario que los miembros de las sociedades tengan un alto grado de compromiso mutuo. TAYLOR, C., «Por qué la democracia necesita el patriotismo», en J. Cohen, Los límites del patriotismo. Identidad, pertenencia Y 'ciudadanía mundial', Barcelona, Paidós, I999, págs. I45-I47.

${ }^{32}$ De hecho, en el mundo occidental contemporáneo los diferentes son, por antonomasia, los extranjeros de religión musulmana. Y en relación con ellos se plantea con agudeza el problema de la lealtad en el doble sentido señalado. Desde el punto de vista cultural, existe la idea implícita de que los musulmanes son separacionistas y desleales, y que adhieren a una religión anti-moderna, sexista y violenta. SARTER, F., «Intégrer l'Islam à l'Europe?», Études, 4I6-I, 20I2, págs. 45-56. Por otro lado, desde el punto de vista de la lealtad al contrato social, parece haber en el ambiente la persistente idea de que el Islam y los principios democráticos son contrapuestos. Gianni, M., «Una visión de Europa occidental: reflexiones sobre la integración de los musulmanes en sociedades secularizadas», en E. Ruiz-Vieytez y G. Urrutia, Derechos humanos y diversidad religiosa, Bilbao, Instituto de Derechos Humanos Pedro Arrupe, 20Io, pág. 86. La percepción sobre los valores imperantes en las comunidades musulmanas genera el temor a que su presencia en los Estados desarrollados afecte la cohesión social y lleve a la violencia y a la pérdida de libertades. VASTA, E., «Why current critique to multiculturalism miss the point?», Centre on Migration, Policy and Society - working papers 53, 2007, pág. I9. 
cumplir el contrato pasen a formar parte de él (en hipótesis y en algún momento, al menos), mientras que el nacionalista puede considerar que la nación está compuesta sólo por los que orgánicamente forman parte de ella, y que toda asimilación es imposible.

La cuestión de la lealtad de los extranjeros aparece insistentemente en el pensamiento de Giovanni Sartori. El autor italiano teme una crisis de la democracia a causa de la llegada de enemigos culturales ${ }^{33}$. Sartori sostiene que resulta indispensable la existencia de un mínimo constitucional al que todos adhieran ${ }^{34}$. Se trata del mínimo constitucional conformado por los principios fundamentales, esencialmente el principio fundamental acerca de cómo deben resolverse los conflictos. Sobre este mínimo constitucional es necesario el consenso, que se logra mediante el ajuste de intereses y puntos de vista divergentes ${ }^{35}$. Hasta aquí pues una lectura de la lealtad en términos contractuales. Sin embargo, el autor italiano va más allá. En la perspectiva de Sartori, el extranjero, o al menos algunos extranjeros, es disidente. Para Sartori los extranjeros que llegan a los países occidentales son beneficiarios de un sistema que no han construido. Y por ello, en virtud del principio de reciprocidad, están en deuda con las sociedades de acogida. Y esta deuda se paga con integración cultural. La ciudadanía no puede recibirse gratuitamente ${ }^{36}$.

Exploremos finalmente una cuarta explicación. Se trata de la justificación pragmática para la limitación de los derechos de los extranjeros. Esta justificación no entra en consideraciones de fondo, y se limita a dar razones coyunturales para tal limitación. Los argumentos pragmáticos pueden asumir, por ejemplo, la forma siguiente: «Dado que nosotros somos una sociedad xenófoba, es mejor que no vengan extranjeros, porque lo pasarán muy mal».

En las concretas legislaciones de los diferentes países estos cuatro argumentos permiten, en grado diverso, entender el funcionamiento de la legislación de extranjería.

Así, el argumento egoísta sirve de hecho para explicar varios aspectos de la legislación migratoria de muchos países. Por ejemplo, el hecho de que los permisos de residencia se otorguen a quienes pueden demostrar que tienen un puesto de trabajo y, más importante aún, que se restrinja el acceso a esos puestos (y consiguientemente a los permisos de residencia) en consideración de las particularidades del mercado de trabajo nacional. Así, si hay puestos vacantes que no pueden ser cubiertos por nacionales, se abre la puerta (para esos puestos) a los extranjeros. Si los puestos pueden ser cubiertos por nacionales, los extranjeros son excluidos. También permite explicar porqué la ampliación de los mercados, mediante la conversión de los mercados nacionales en mercados

\footnotetext{
${ }^{33}$ SARTORI, G., La sociedad multiétnica: Pluralismo, multiculturalismo y extranjeros, Madrid, Taurus, 20oI, págs. 53-55.

${ }^{34}$ SARTORI, G., La sociedad multiétnica: Pluralismo, multiculturalismo y extranjeros, cit., pág. I3.

${ }^{35}$ Para Sartori, es necesario el consenso en el terreno de los Fundamentals, de los principios fundamentales. Y el consenso más importante de todos es el consenso acerca de las reglas de resolución de los conflictos que es, en democracia, la regla mayoritaria. A partir de ese momento resulta lícito entrar en conflicto sobre las policies, sobre la solución de las cuestiones concretas, en el campo de las políticas de gobierno. Pero el consenso no debe entenderse como unanimidad. El consenso pluralista se basa en un proceso de ajuste entre mentes e intereses discrepantes. SARTORI, G., La sociedad multiétnica: Pluralismo, multiculturalismo y extranjeros, cit., págs. 36-37.

${ }^{36}$ Este tipo de propuestas pueden entenderse como incluidas entre aquellas que, según De Lucas, se refieren a la diversidad como un riesgo para la democracia porque afirman la necesidad de una homogeneidad en sentido fuerte y declaran la incompatibilidad de determinados modelos culturales respecto de la democracia. DE LUCAS, J., Puertas que se cierran: Europa como fortaleza, cit., págs. 82-90.
} 
regionales como es el caso de la Unión Europea o del Mercosur, viene de la mano de la extensión de los derechos de los que gozan los nacionales de un Estado en el territorio de otro.

Pero el criterio egoísta no explica todos los supuestos. No permite explicar, por ejemplo, porqué el cónyuge y los demás miembros de la familia de un nacional que no son ellos mismos nacionales, aunque sean productivamente nulos pueden gozar de derechos de los que no gozan extranjeros talentosos y productivos.

El criterio de la lealtad al contrato social y el criterio esencialista también explican algunas $\operatorname{cosas}^{37}$. Por ejemplo, permiten entender los mecanismos de naturalización: cuando alguien ha vivido durante un cierto tiempo en el territorio de un Estado, puede probar que no ha cometido delitos (demostrando de ese modo su sometimiento a las obligaciones del contrato social) y que ha aprendido la lengua del país (demostrando así cierta asimilación a la esencia de la nación), tiene normalmente la posibilidad de convertirse en nacional de ese Estado y acceder al mismo estatus jurídico que los demás nacionales.

Este argumento es también el que está detrás de la posición de Giovanni Sartori cuando afirma sus dudas sobre la posibilidad de integración de los musulmanes en Europa. Dice el autor: «¿Me equivoco, por ejemplo, al sostener que el inmigrado islámico es para nosotros el más 'distante', el más 'extranjero', y por tanto el más difícil de integrar? Si me equivoco, nadie me lo ha demostrado» ${ }^{38}$. La reticencia a reconocer derechos se sustenta así en la dificultad (o imposibilidad de la integración cultural).

Sin embargo, tampoco esta explicación se aplica a todos los casos. Así, en los casos en que la asignación de la nacionalidad se produce por ius sanguinis, el argumento del contrato social y el de la esencia de la nación pueden ser completamente inoperantes. ¿Por qué el hijo de un español que ha nacido en China, no habla una sola palabra de la lengua de Cervantes, jamás ha pisado España y no tiene ni idea acerca de cómo hacer una tortilla de patatas puede adquirir la nacionalidad española y, de este modo, tener los mismos derechos que un señor que ha nacido y vivido toda su vida en Zaragoza, contribuyendo al desarrollo del país y demostrando su lealtad al contrato social? Inversamente, en los casos en que la adquisición de la nacionalidad se produce por ius soli, alguien que ha nacido en el territorio del Estado y lo ha abandonado al cabo de unos días tendrá más derechos en ese Estado que quien lleva viviendo ahí varios años, mientras que es mucho más probable que el segundo, y no el primero, esté asimilado a la forma de vida y haya demostrado lealtad al contrato social que aglutina a los nacionales del Estado ${ }^{39}$.

El argumento pragmático suele venir en refuerzo de alguno de los otros tres. Si volvemos a nuestro ejemplo español de la restricción del acceso a la sanidad de los

${ }^{37}$ Como explica Javier de Lucas, la nacionalidad, en el sentido de vínculo jurídico, depende de la nacionalidad en el sentido identitario: sólo son nacionales (es decir, tienen un vínculo jurídico privilegiado con el Estado) y por ello ciudadanos plenos quienes pertenecen a la Nación en sentido cultural. De este modo, el mito moderno de la identidad funciona como mecanismo de cohesión, pero también como medio de exclusión de los diferentes. Por eso es que se puede predicar de la historia de los Estados el lema en el principio fue la exclusión. DE LuCAS, J., Puertas que se cierran: Europa como fortaleza, cit., págs. 2I-29.

${ }^{38}$ SARTORI, G., «El Islam y la inmigración», Claves de razón práctica, II7, 200I, pág. I3.

${ }^{39}$ Dado que hemos hablado más arriba de Francisco De Vitoria, resulta de interés en este punto recordar que fue un defensor del ius soli como criterio de nacionalidad. Decía De Vitoria: «Parece ser de derecho de gentes que quien ha nacido en una ciudad se llame y sea ciudadano de ella». DE Vitoria, F., Sobre el poder civil; Sobre los indios; Sobre el derecho de la guerra, cit., pág. I35. 
extranjeros en situación irregular, veremos en efecto cómo se articula el argumento pragmático. La justificación podría presentarse así: dado que determinados extranjeros no son necesarios para nuestro sistema económico, no les autorizamos a estar en nuestro territorio (argumento egoísta); si se quedan a pesar de todo, dado que su presencia aquí es indeseada, no les permitimos acceder al sistema sanitario ya que, en definitiva, sólo nos interesa la buena salud de los extranjeros que son útiles a nuestro sistema económico (corolario del argumento egoísta). Claro que si lleváramos a sus últimas consecuencias el argumento egoísta deberíamos privar a todos los extranjeros improductivos del acceso a la sanidad, y no sólo a los extranjeros que, siendo improductivos, no han accedido a un permiso de residencia (por ejemplo, deberíamos privar del acceso a la sanidad a los extranjeros que tienen un permiso de residencia por razones no laborales, por ejemplo familiares). Sin embargo, esto último sería más difícilmente aceptable para la opinión pública, así que la restricción al acceso a la sanidad se hace sólo respecto de los extranjeros sin permiso de residencia (argumento pragmático que restringe el argumento egoísta).

Veamos otro ejemplo de argumento pragmático. Una de las críticas recibidas por la tesis de Sartori sobre la dificultad de integrar a los inmigrantes islámicos es que no estaría empíricamente demostrado que la religión islámica se asocia necesariamente con una negación de las reglas del pluralismo. La respuesta de Sartori es: «Sí, acepto que la verificación empírica de mi tesis es insuficiente; pero, ¿no será demasiado tarde cuando sea suficiente?». El argumento no es siquiera el argumento egoísta («la presencia de los inmigrantes de religión musulmana nos es perjudicial y por lo tanto hay que limitarla»), sino una vertiente pragmática de ese argumento («no sabemos si esto será bueno o malo para nosotros, por si acaso lo limitamos»).

\section{Conclusiones: la inseguridad de los derechos}

Los cuatro argumentos que presentamos permiten, cada uno de ellos parcialmente, explicar el tratamiento excluyente de los extranjeros en los ordenamientos jurídicos nacionales, y la situación de inseguridad permanente que afecta a su precario estatuto jurídico. Desde una perspectiva liberal respetuosa de los derechos humanos, es seguramente fácil descalificar el primer, el tercer y el cuarto argumento, así como las tergiversaciones que pueden afectar al segundo.

El primer argumento puede rechazarse con facilidad desde cualquier teoría de la justicia que no sea puro cinismo. En efecto, prácticamente desde cualquier concepción de la justicia puede rebatirse un argumento que, en realidad, es un no-argumento: es la expresión del instinto egoísta validado por la fuerza. También es posible descalificar fácilmente el cuarto argumento, que es igualmente un no-argumento, una simple consideración de las circunstancias que permiten la exclusión de derechos.

Es curioso ver cómo el argumento (o no-argumento) egoísta suele venir de la mano de la defensa neoliberal a ultranza del libre mercado. Esto, desde nuestro punto de vista, es una inconsecuencia. Porque si de lo que se trata es defender de modo coherente el libre mercado, nada mejor que permitir no sólo la libre circulación de mercaderías y capitales, sino también de personas. Y si los extranjeros son más aptos y capaces que los nacionales, o venden su trabajo por salarios más bajos, pues tanto mejor, porque eso hace más eficiente al mercado. 
Por otra parte, el problema con el tercer argumento no es la existencia de vínculos nacionales en sí misma, ni su utilización simbólica como forma de refuerzo de los lazos de solidaridad al interior de la comunidad política, sino que se utilice la nación como criterio de exclusión en los derechos. El problema, en efecto, no es la nación en sí misma, sino su esencialización como criterio determinante de la exclusión.

Tal vez desde una perspectiva liberal respetuosa de los derechos el criterio más atendible sea el contractualista. Al fin y al cabo, parece lógico que quien quiera beneficiarse de determinados derechos también esté sometido a ciertos deberes. Sin embargo, el argumento del contrato no alcanza tanto como para excluir a los extranjeros de los derechos de la ciudadanía, sino a lo sumo para modular el acceso (de cualquier persona, nacional o extranjera) a los derechos en función de la correlativa parte en las obligaciones. La clave está en que todo aquél que quiera formar parte del contrato ciudadano y se comprometa a las obligaciones que el contrato le impone, con independencia de si el azar de su nacimiento o su sangre lo han hecho nacional o extranjero, pueda disfrutar también de los derechos de la ciudadanía.

\section{V.Bibliografía citada}

BLOCH, M., La sociedad feudal, Madrid, Akal, I987.

CASANOVA, J., «Immigration and the new religious pluralism: a European Union - United States comparison», en G. Levey y T. Modood, Secularism, religion and multicultural citizenship, Cambridge, Cambridge University Press, 20I0, págs. 139-163.

Combacau, J. y Sur, S., Droit International Public, París, Montchrestien, I999.

De Courcelles, D., «Pensée théologique et événement: droit de conquête et droit des gens dans l'empire espagnol du XVIe siècle», en C. Val Julian, La conquête de l'Amérique Espagnole et la question du droit, Fontenay-aux-Roses, ENS, I996, págs. I5-31.

DE LuCAS, J., Puertas que se cierran: Europa como fortaleza, Barcelona, Icaria, I996.

— «Nuevas estrategias de estigmatización. El Derecho, frente a los inmigrantes», en G. Portilla, Mutaciones de Leviatán. Legitimación de los nuevos modelos penales, Madrid, Akal, 2005, págs. 205-219.

— «Inmigrantes. Del estado de excepción al Estado de derecho», Oñati Socio-Legal Series, I-3, 2oII, págs. I-I4.

De Vitoria, F., Sobre el poder civil; Sobre los indios; Sobre el derecho de la guerra, Madrid, Tecnos, 2007.

DíeZ de Velasco, M., Instituciones de Derecho Internacional Público, Madrid, Tecnos, 2007.

FinLEY, M. I., Ancient slavery and modern ideology, Harmondsworth, Penguin, I983.

García Amado, J. A., «¿Por qué no tienen los inmigrantes los mismos derechos que los nacionales?», Revista de Derecho Migratorio y Extranjería, 3, 2003, págs. 9-28.

GiANNI, M., «Una visión de Europa occidental: reflexiones sobre la integración de los musulmanes en sociedades secularizadas», en E. Ruiz-Vieytez y G. Urrutia, Derechos humanos y diversidad religiosa, Bilbao, Instituto de Derechos Humanos Pedro Arrupe, 20ıo, págs. 8I-I04.

Gomez, T., Droit de conquête et droit des indiens, Paris, Armand Colin, I996.

Habermas, J., Más allá del Estado nacional, Madrid, Trotta, 200I.

KLEIN, H. S., La esclavitud africana en América Latina y el Caribe, Madrid, Alianza, I986.

LEVEY, G. B., «Secularism and religion in a multicultural age», en G. Levey y T. Modood, Secularism, religion and multicultural citizenship, Cambridge, Cambridge University Press, 20ıо, págs. I24 . 
Nussbaum, M. C., Liberty of conscience. In defense of America's traditions of religious equality, Nueva York, Basic Books, 2009.

Pastor Ridruejo, J. A., Curso de Derecho Internacional Público y Organizaciones Internacionales, Madrid, Tecnos, 2012.

Peces-BarbA, G., «Introducción», en G. Peces-Barba, Ley y conciencia. Moral legalizada y moral crítica en la aplicación del derecho, Madrid, Universidad Carlos III, I993, págs. 9-I7.

PÉREZ-PRENDES, J. M., Instituciones medievales, Madrid, Síntesis, I997.

Quoc Dinh, N., Droit international public, Paris, Librairie Générale de Droit et de Jurisprudence, I994.

Remiro Brotons, A., Derecho Internacional, Valencia, Tirant lo Blanch, 2007.

SARTER, F., «Intégrer l'Islam à l'Europe?», Études, 4I6-I, 20I2, págs. 45-56.

SARTORI, G., «El pluralismo y sus interpretaciones», Revista de Occidente, I88, I997, págs. I3I-I47.

— La sociedad multiétnica: Pluralismo, multiculturalismo y extranjeros, Madrid, Taurus, $200 \mathrm{I}$.

— «El Islam y la inmigración», Claves de razón práctica, II7, 200I, págs. IO-I5.

Susín BETRÁn, R., Fronteras y retos de la ciudadanía. El gobierno democrático de la diversidad, Logroño, Perla Ediciones, 2012.

TAYlor, C., The Ethics of Authenticity, Cambridge, Harvard University Press, I99I.

— «Por qué la democracia necesita el patriotismo», en J. Cohen, Los límites del patriotismo. Identidad, pertenencia $y$ 'ciudadanía mundial', Barcelona, Paidós, I999, págs. I45-I47.

VASTA, E., «Why current critique to multiculturalism miss the point?», Centre on Migration, Policy and Society - working papers, 53, 2007, págs. I-39. 